\title{
Study on the Modification Formula of Earth Material Compound with Cement and Gravel by Single Lattice Theory
}

\author{
Kun Zhang $\mathbb{D}^{1,2}$ Bai-Ru Lu, ${ }^{3}$ Yi-Hong Wang, ${ }^{4}$ Zhan Qu, ${ }^{1}$ and Le Qu ${ }^{1}$ \\ ${ }^{1}$ Postdoctoral Innovation Base/Infrastructure Department, Xi'an Shiyou University, Xi'an 710065, China \\ ${ }^{2}$ Xi'an Shiyou University Shaanxi Key Laboratory of Well Stability and Fluid \& Rock Mechanics in Oil and Gas Reservoirs, \\ Xi'an 710065, China \\ ${ }^{3}$ School of Human Settlements, Xi'an Eurasia University, Xi'an 710065, China \\ ${ }^{4}$ School of Civil Engineering, Chang'an University, Xi'an 710061, China
}

Correspondence should be addressed to Kun Zhang; 491543584@qq.com

Received 21 June 2019; Revised 13 August 2020; Accepted 3 December 2020; Published 21 December 2020

Academic Editor: Lei Wang

Copyright (c) 2020 Kun Zhang et al. This is an open access article distributed under the Creative Commons Attribution License, which permits unrestricted use, distribution, and reproduction in any medium, provided the original work is properly cited.

Gravel and cement can effectively improve the low strength of traditional Earth materials. There have been few studies on test methods for raw soil-based composite admixtures. By introducing the theory of single lattice formula testing, the compressive strength of 10 formulas and 60 modified raw soil cubic specimens were tested. The failure process, failure mode, and compressive strength of specimens were studied. The effects of different formulations of raw soil on strength, peak displacement, and dispersion were analyzed. The results showed that cement content had a significant effect on the compressive strength and dispersion of earth material specimens. The optimal modification formula of cement, gravel, and raw soil was determined to be 0.1/0.08/0.82 (mass ratio). At the same time, the applicability of the test method was verified, which can be used as a reference for the experimental study on modification formulations of earth materials.

\section{Introduction}

Earth materials are some of the oldest local building materials and are widely used in dwelling construction all over the world. In fact, one-third of the world's population still lives in earthen dwellings $[1,2]$. In the last twenty years, this original material has gained new attention from the construction industry because of its low energy consumption and excellent ability to regulate indoor temperature and humidity $[3,4]$. As an important part of traditional architecture, it has the advantages of low energy consumption, good thermal performance, sound absorption, radiation, and environmental protection and can serve as a model for "green architecture" [5-7]. However, the weak strength of raw materials for native construction has always been considered a drawback by structural engineers. Therefore, there has been much research on the modification of raw earth materials all over the world. At present, the modification methods of raw soil materials can be divided into physical modification, mechanical modification, and chemical modification $[8,9]$.

Physical modification is to select well graded soil material or add reinforced material into soil material [10]. Mechanical modification refers to the modern manufacturing process. Mechanical dynamic compaction is used to increase the compactness of raw soil foundation blocks [11]. Chemical modification is the incorporation of chemical reagents into materials [12]. Among the main curing agents in modifying earth materials are cement, lime, and fly ash. Spence and Cook of the University of Chichester have studied the modification of earth materials with a certain amount of cement and carried out experiments with Alfred et al. Their results showed that when the cement content is $5 \%$, cement solidified. Also, adobe has good durability and water absorption performance [13, 14]. Stephane Hans of the University of Lyon and others have proposed the modification of raw soil materials with cement and lime and calculated the damage of existing native 
buildings in earthquakes [15]. Steve Burroughs of Australia has done stability testing to quantify the linear shrinkage of natural soils and the amount of cement and lime mixed into them [7]. Milani and Labaki studied the sustainability of the original soil materials and evaluated the modified soil materials mixed with cement and lime. The results showed that $7.5 \mathrm{wt} \%$ lime and $10 \mathrm{wt} \%$ cement have been mixed into the soil to obtain promising mixture materials [4]. Ziegler used fiber materials to modify the raw soil-based materials. This method formed a three-dimensional fiber network inside the materials, which significantly improved the compressive strength and shear strength of the raw soil-based materials [16].

In a word, experimental results have been obtained in the earth modification field. However, the traditional orthogonal test cannot completely solve the problem of modifying material formulas. A single admixture and test methods are not unified from different studies and the existing research results scattered. Modified additives of materials often have complex chemical reactions in soil and modified earth materials are not green and environmentally friendly. In this study, based on the theory of single grid test design, the composite test of raw soil materials with multiple admixtures is carried out. Using physical modification methods according to research results from this research group, a modified formula test was carried out with gravel (gravel, $10-20 \mathrm{~mm}$ diameter), cement, and raw soil [17]. The modified formula of earth material was studied using the Voth single lattice model $[18,19]$. Sixty specimens were produced for compressive strength testing and the strength, peak displacement, discrete reference parameters, parameter analysis, and elimination element regression were used to draw a triangular contour map. From these results, a reasonable modification test method and formula were presented. The research provided suggestions for similar studies in the future.

\section{Voth Single Lattice Theory}

In the design of the test, the test level is a factor of each factor accounted for in the proportion of the total, with the percentage of all $\boldsymbol{P}$ factors in the experiment being the percentage of the total. The total composition must be equal to 1 $(100 \%)$. This kind of design is called formula design, also known as mix design [20].

The level values of $P$ factors in formulation design were

$$
x_{1}, x_{2}, x_{3}, \ldots, x_{p} \quad\left(0 \leq x_{i} \leq 1,0 \leq i \leq p\right) .
$$

Here, $\sum_{i=1}^{p} x_{i}=1, x_{i}$ is called the scaling factor. If using geometric terms, with $\boldsymbol{p}$ called the dimension, $x_{i}$ is a point on the $\boldsymbol{P}$-dimensional plane in Hypothesis 3 factor formulation test. According to $\boldsymbol{P}$ component variables $x_{i}(0 \leq i \leq p)$ in the formulation design. Here, $y$ is the response variable and the mathematical model can be established:

$$
y=f\left(x_{1}, x_{2}, \ldots, x_{p}\right)+\varepsilon
$$

where $\varepsilon$ is the random error and observation values $y_{1}, y_{2}, \ldots y_{n}$ from reaction variables $n$ times. The regression coefficient of the function was estimated and the regression equation obtained:

$$
\widehat{y}=f\left(x_{1}, x_{2}, \ldots, x_{p}\right) .
$$

The above is a polynomial of degree $d$ and the formula test determined by the number of factors $P$ and the number $d$ of directional functions. A formula test was represented by $M\{p, d\}$. Thus, it was also called a single lattice design. Here, $p=n, d=m$.

A significance test of multivariate linear regression equation by $F$-test was used with the square sum $\left(S S_{T}\right)$, the regression square sum $\left(S S_{R}\right)$, and the sum of squares of residuals $\left(S S_{e}\right)$, and $F$ and $R^{2}$ are calculated finally.

After passing the F-test, the regression equation was solved and the isoline map drawn as a triangular coordinate map to determine the optimal mixing ratio.

In the design of the single lattice formulation, there was no restriction on $x_{i}\left(0 \leq x_{i} \leq 1\right.$ and $\left.0 \leq i \leq p\right)$. For the formulation design of restricted ingredients, restricted ingredients were expressed in terms of $z$. If there are lower bounds, upper bounds, or both upper and lower bounds for component $z_{i}, L_{i}$ represented the lowest proportion of component $i$ and the highest proportion of component $U_{i}$, that is, the upper and lower bounds of $z_{i}$. The hypothesis was

$$
z_{1}+z_{2}+\cdots+z_{p}=1 \quad 0 \leq L_{i} \leq z_{i} \leq 10 \leq i \leq p .
$$

Because the formula test area was simple, the original ingredients could be changed. A new set of components was defined in the executable formulation area and the change range of the new components still between 0 and 1 . The appropriate formulation design structure model was obtained in the restricted area. The component was redefined as the $L$-coding component. The coding component $x_{i}$ of $i$ was

$$
\begin{gathered}
x_{i}=\frac{z_{i}-L_{i}}{1-L}, \\
L=\sum_{i=1}^{p} L_{i} \leq 1,
\end{gathered}
$$

where $z_{i}$ was the actual occupancy ratio after conversion.

\section{Experimental}

3.1. Experimental Design. According to the previous research results in this research group, adding cement materials to raw soil improves soil cohesion and adding gravel filled pores in the raw soil, thus improving the overall mechanical properties of the material. The cement content was not $<3 \mathrm{wt} \%$ and the gravel content not $<5 \mathrm{wt} \%$. As raw soil was the main material, the content cannot be $<75 \mathrm{wt} \%$. Here, $z_{1}$ was cement, $z_{2}$ gravel, and $z_{3}$ raw soil:

$$
z_{1}+z_{2}+z_{3}=1 \quad z_{1} \geq 0.03 z_{2} \geq 0.05, z_{3} \geq 0.75 \text {. }
$$

Because there were three kinds of admixtures, the triangle single grid method was adopted, and ten points in the graph were selected as test-coding points. A single lattice 
test-coding diagram is shown in Figure 1 and a limit zone diagram of cement, gravel, and raw soil content in Figure 2. The black spot in Figure 1 is the test mix ratio. Photocopy in Figure 2 is the limited area of material composition.

As can be seen from Section 2 and formulas (4) and (5), $z_{1 n s i}=0.03+0.17 x_{1 n s i}(i=1-10), \quad z_{2 n s i}=0.05+0.17 x_{2 n s i}$ $(i=1-10)$, and $z_{3 n s i}=0.75+0.17 x_{3 n s i}(i=1-10)$.

The calculation results of the experimental grouping formula are shown in Table 1.

3.2. Materials. Soil samples used in this test were loess from the Chang'an District of Xi'an City in China. The optimal loess moisture content was $18.2 \%$ and maximum dry density at $2.04 \mathrm{~g} / \mathrm{cm}^{3}$, according to "Standard of Geotechnical Experiment Methods" (Geotechnical test method standard, 1999) (GBT50123-1999), with the plastic limit at 15\%, liquid limit at 26\%, and plastic index at 11.3 [21]. The results are shown in Table 2. At the same time, the sieving test of loess is carried out, and the results are shown in Table 3 (the particle size distribution). The gravel was gravel $10-20 \mathrm{~mm}$ in diameter. The strength of the cement was 32.5 ordinary Portland cementSchool of Civil Engineering, Chang'an University, Xi' an 710061, China, Shaanxi Qinling Cement). Referring to previous research of this research group, the optimal moisture content of raw soil materials mixed with cement was determined [22]:

$$
\omega=\omega_{0}+0.27 \phi
$$

where $\omega$ is the optimal moisture content of modified raw soil, $\omega_{0}$ at $18.2 \%$, and $\varphi$ the cement content. The moisture content of each group of specimens with a cement-modified formula is shown in Table 4 .

Before experimentation, the earth was passed through a $5 \mathrm{~mm}$ sieve and mixed to optimal moisture content; see Table 4 for water mixing materials. Using a mold developed by this research group, 60 samples of $100 \times 100 \times 100 \mathrm{~mm}$ cubes were prepared from each earth using a method of jack compression. The preparation device and sample are shown in Figure 2 [23].

3.3. The Loading Device. Molded specimens were cured in a standard curing room and then tested for compressive strength. Here, the specimens were placed in a room at $25-30^{\circ} \mathrm{C}$ and $55-60 \%$ humidity to cure for $28 \mathrm{~d}$. Using an MTS-500 universal uniaxial load tester (Manta Testing Systems Inc., Mississauga, Canada), test data regarding the relationship between displacement and load was automatically collected. A sample was centered and placed horizontally on the ball support, with the sample in close contact with the machine before test initiation. The loading rate was set to $1 \mathrm{~mm} / \mathrm{min}$ and $30 \%$ of the peak load taken as the final condition of a test after peak loading, which ensured normal machine operation. The test procedure is shown in Figure 3.

At the initial stage of loading, cracks did not immediately appear on soil cube surfaces and no other visible cracks appeared. With increased load, specimen corners cracked, cracks developed along the specimen's stress direction, and the specimen did not immediately break. As the load continued to increase to peak load, many vertical cracks appeared on the test piece surface, along with swelling cracks on the piece's middle surfaces, and portions of the skin soil fell off. With further increased load, cracks continued to develop until the specimen was completely destroyed, accompanied by rapidly decreased load, bearing capacity loss, and failure mode appearing as a typical "hourglass."

\section{Results and Discussion}

4.1. Compressive Strength Analysis. The average value of protest strength of each group of specimens is taken as the compressive strength of the test samples. The experimental results are shown in Table 5 .

Referring to Table 5, the compressive strength of the modified raw soil with gravel and cement is significantly higher than that of the raw soil. The compressive strength of the modified specimen is 1.16-3.55 times that of the raw soil specimen.

Compared with NS3, NS5, and NS2 group, when the cement content is $3 \%$ and the gravel content is $5 \%, 13.5 \%$, and $22 \%$, the compressive strength of the specimen is 5.77 $\mathrm{MPa}, 4.39 \mathrm{MPa}$, and $3.75 \mathrm{MPa}$. The results show that when the cement content is fixed, the strength of the specimen decreases with the increase of the gravel content.

Compared with NS3, NS6, and NS1 group, when the gravel content is $5 \%$ and the cement content is $3 \%, 11.5 \%$, and $20 \%$, the compressive strength of the specimen is 5.77 MPa, $8.87 \mathrm{MPa}$, and $11.51 \mathrm{MPa}$. The results show that when the gravel content is fixed, the strength of the specimen increases with the increase of the cement content.

According to a large number of research results, the compressive strength of raw soil-based materials with gravel and cement is higher than that with gravel or cement alone [参考文献]. The strength of gravel is obviously higher than that of soil. However, when the gravel is mixed with the raw soil alone, the bond performance between the gravel and the soil is poor, which leads to the reduction of the time compression performance. As a cementitious material, cement can react with water molecules in the soil to consolidate soil particles and fill the pores in the soil, which improves the particle size distribution and increases the material density. The gravel is wrapped by cement soil and closely bonded, acting as coarse aggregate, playing a skeleton role, and resisting deformation when the material is under pressure, and the material strength is significantly improved.

4.2. Formula Discussion. The raw soil-modified cubic specimens consisted of sand $\left(z_{1}\right)$, gravel $\left(z_{2}\right)$, and raw soil $\left(z_{3}\right.$, Table 1). There was more than one reaction variable $y$ in the formulation of specimens considering the test results. There were three parameters that reflected the advantages and disadvantages of the modified specimens. The first response variable was the cubic compressive strength $\left(y_{1}\right)$, the second response variable was the cubic peak displacement $\left(y_{2}\right)$, and the third response variable was the cubic Standard deviation $\left(y_{3}\right)$. Integrating Tables 1 and 3 yielded Table 6 . 


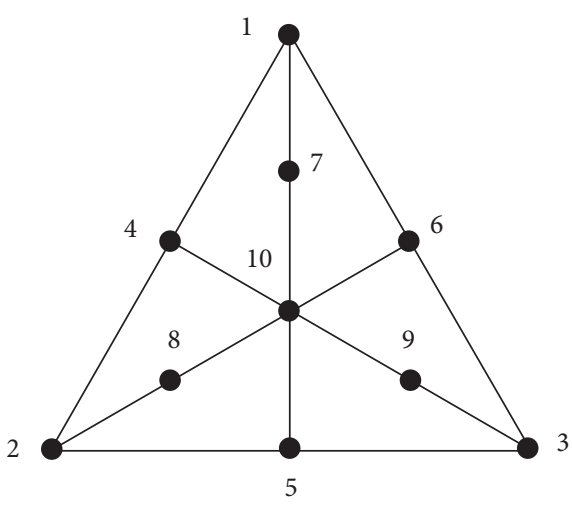

(a)

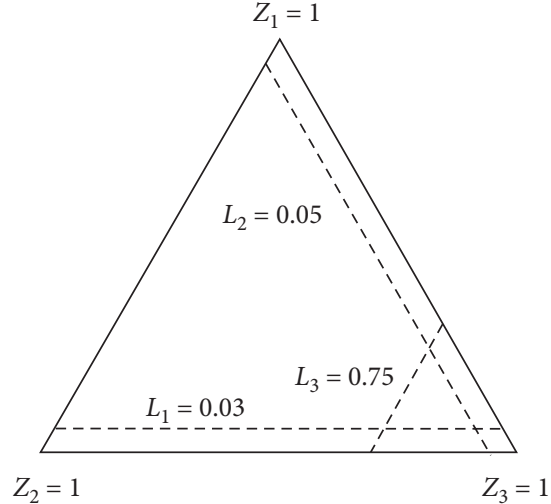

(b)

Figure 1: (a) Triangular simplex design test points. (b) Limited areas of cement, gravel, and raw soil content.

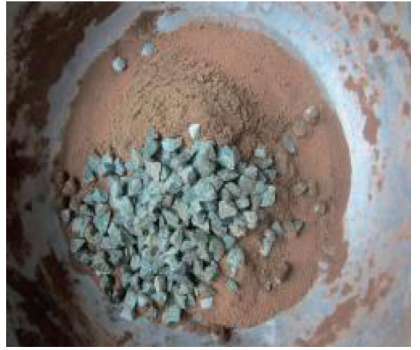

(a)

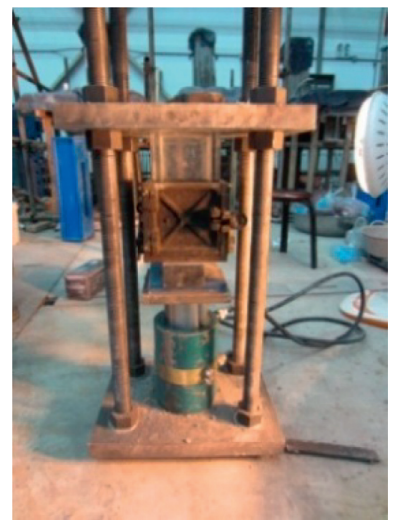

(d)

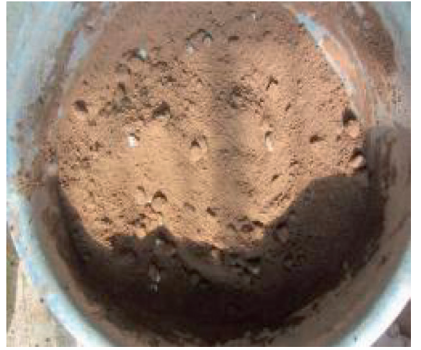

(b)

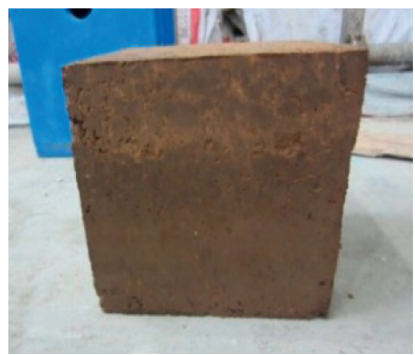

(e)

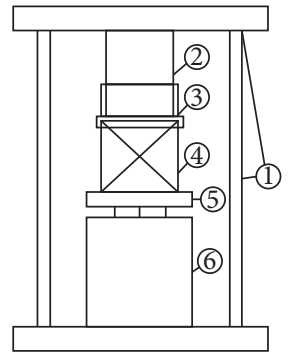

(1) Counterforce frame

(2) Pressing plate

(3) Guard plate

(4) Specimen mold

(5) Steel plate

(6) Jack

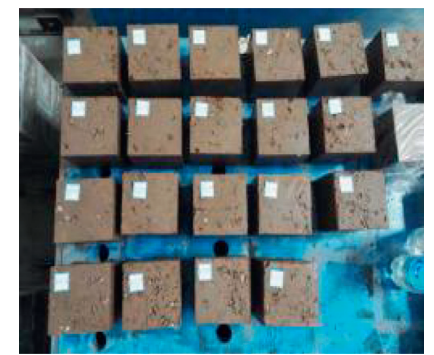

(f)

Figure 2: Manufacturing equipment and test specimens. Raw material (a), mixture mixing, (b) schematic diagram of the device (c), specimen making (d), specimen (e), and specimen maintenance (f).

(1) Regression analysis of response variable $y_{1}$ was carried out with reference to Table 4 . The calculation was simplified by examining the first-order polynomial for the regression model $\hat{y}=f(x)=a x_{1}+b x_{2}+c x_{3}$ (Table 7), which showed that the coefficient of determination was $R^{2}=0.9249$ by linear regression. According to the $F$-test, the linear regression equation was significant and the primary regression model concluded to be scientific and reasonable. The polynomial coefficients calculated by MATLAB are shown in Table 8 . The corresponding regression equation was $y_{1}=12.23 x_{1}+4.13 x_{2}+5.92 x_{3}$.
According to the coordinates of the equation solution in Table 9, a contour map corresponding to the equation was drawn in triangular coordinates using Origin 9.0 drawing software (Figure 4 ).

Parameters $x_{1}, x_{2}$, and $x_{3}$ represented the admixtures of cement, gravel, and raw soil, respectively (Figure 4). The gradient of the isoline decreased from $x_{1}$ point to the $x_{2} x_{3}$ coordinate axis step by step. The isoline basically deviated to the $x_{1} x_{2}$ coordinate axis. The average strength line fell on the $x_{1} x_{2}$ and $x_{1} x_{3}$ axes, which showed that the cement content of these three admixtures played a major role in compressive 
TABLE 1: Axis point extended simplex lattice design scheme for cement and gravel mixed with the modified raw soil test.

\begin{tabular}{|c|c|c|c|c|c|c|}
\hline \multirow{2}{*}{ Test formation } & \multicolumn{3}{|c|}{ Test coding } & \multicolumn{3}{|c|}{ Mix ratio of test materials (by wt) } \\
\hline & $x_{1}$ & $x_{2}$ & $x_{3}$ & $z_{1}$ & $z_{2}$ & $z_{3}$ \\
\hline NS1 & 1 & 0 & 0 & 0.20 & 0.05 & 0.75 \\
\hline NS2 & 0 & 1 & 0 & 0.03 & 0.22 & 0.75 \\
\hline NS3 & 0 & 0 & 1 & 0.03 & 0.05 & 0.92 \\
\hline NS4 & $1 / 2$ & $1 / 2$ & 0 & 0.12 & 0.14 & 0.75 \\
\hline NS5 & 0 & $1 / 2$ & $1 / 2$ & 0.03 & 0.14 & 0.84 \\
\hline NS6 & $1 / 2$ & 0 & $1 / 2$ & 0.12 & 0.05 & 0.84 \\
\hline NS7 & $2 / 3$ & $1 / 6$ & $1 / 6$ & 0.14 & 0.08 & 0.78 \\
\hline NS8 & $1 / 6$ & $2 / 3$ & $1 / 6$ & 0.06 & 0.16 & 0.78 \\
\hline NS9 & $1 / 6$ & $1 / 6$ & $2 / 3$ & 0.06 & 0.08 & 0.86 \\
\hline NS10 & $1 / 3$ & $1 / 3$ & $1 / 3$ & 0.09 & 0.11 & 0.81 \\
\hline
\end{tabular}

TABLE 2: The index of soil-based materials.

Name Maximum dry density $P_{d},\left(\mathrm{~g} / \mathrm{cm}^{3}\right)$ Optimum moisture content $w_{0}$, (\%) Plastic limit $w_{p},(\%)$ Liquid limit $w_{L}$, (\%) Plastic index

\begin{tabular}{llllll}
\hline Loess & 2.04 & 18.2 & 15 & 26 & 11 \\
\hline
\end{tabular}

TABLE 3: Size distribution of loess screening result.

\begin{tabular}{lcccccrr}
\hline Particle size $(\mathrm{mm})$ & $\geq 4.75$ & $4.75 \sim 2.36$ & $2.36 \sim 1.18$ & $1.18 \sim 0.60$ & $0.60 \sim 0.30$ & $0.30 \sim 0.15$ & $\leqq 0.15$ \\
\hline Particle content $(\%)$ & 0.00 & 14.07 & 20.63 & 17.00 & 14.00 & 8.40 & 26.00 \\
\hline
\end{tabular}

TABLE 4: The moisture content of each group of specimens containing cement.

\begin{tabular}{lllllllllll}
\hline Test formation & NS1 & NS2 & NS3 & NS4 & NS5 & NS6 & NS7 & NS8 & NS9 & NS10 \\
\hline Moisture content & 0.23 & 0.19 & 0.19 & 0.21 & 0.19 & 0.21 & 0.22 & 0.20 & 0.20 & 0.20 \\
\hline
\end{tabular}

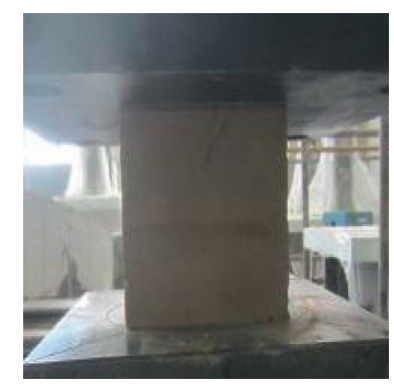

(a)

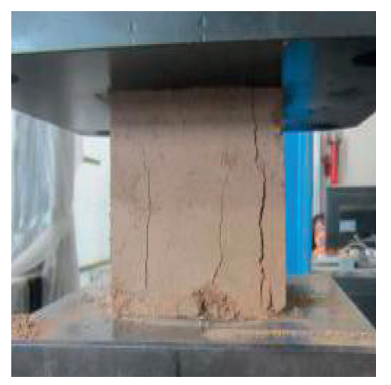

(b)

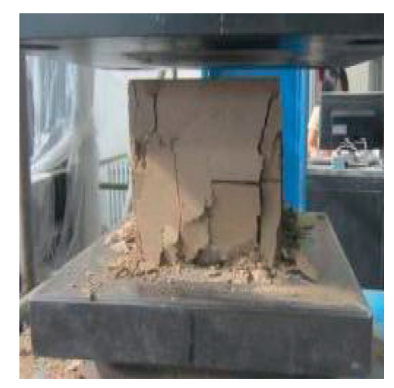

(c)

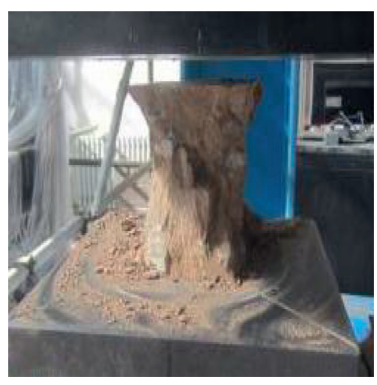

(d)

Figure 3: Compressive strength tests of raw soil material cubes. Loading (a), cracking (b), damage (c), and completely destroyed (d).

TABLE 5: Test results of compressive strength of specimens mixed with cement, gravel, and raw soil.

\begin{tabular}{|c|c|c|c|c|c|}
\hline \multirow{2}{*}{ Test formation } & \multirow{2}{*}{ Peak load $(\mathrm{kN})$} & \multirow{2}{*}{ Peak displacement (mm) } & \multicolumn{3}{|c|}{ Compressive strength } \\
\hline & & & Average of strength (MPa) & Standard deviation & Coefficient of variation \\
\hline NS1 & 115.12 & 3.57 & 11.51 & 1.290 & 0.112 \\
\hline NS2 & 37.52 & 2.97 & 3.75 & 0.447 & 0.119 \\
\hline NS3 & 57.75 & 4.11 & 5.77 & 0.492 & 0.085 \\
\hline NS4 & 79.73 & 3.33 & 7.97 & 2.202 & 0.276 \\
\hline NS5 & 43.92 & 3.43 & 4.39 & 1.108 & 0.252 \\
\hline NS6 & 88.74 & 3.81 & 8.87 & 0.971 & 0.109 \\
\hline NS7 & 111.02 & 3.55 & 11.10 & 1.067 & 0.096 \\
\hline NS8 & 68.12 & 3.58 & 6.81 & 1.178 & 0.173 \\
\hline NS9 & 72.06 & 3.70 & 7.21 & 1.005 & 0.139 \\
\hline NS10 & 69.15 & 3.70 & 6.91 & 0.734 & 0.106 \\
\hline Raw soil & 32.42 & 2.7 & 3.24 & 0.393 & 0.121 \\
\hline
\end{tabular}


TABLE 6: Axis point extended simplex lattice design and the result of lower limit component boundary in mixed cement and gravel modified with raw soil.

\begin{tabular}{|c|c|c|c|c|c|c|c|c|c|}
\hline \multirow{2}{*}{ Test formation } & \multicolumn{3}{|c|}{ Test coding } & \multicolumn{3}{|c|}{ Mix ratio of test materials } & \multicolumn{3}{|c|}{ Response variables } \\
\hline & $x_{1}$ & $x_{2}$ & $x_{3}$ & $z_{1}$ & $z_{2}$ & $z_{3}$ & $y_{1}$ & $y_{2}$ & $y_{3}$ \\
\hline NS1 & 1 & 0 & 0 & 0.20 & 0.05 & 0.75 & 11.51 & 3.57 & 1.290 \\
\hline NS2 & 0 & 1 & 0 & 0.03 & 0.22 & 0.75 & 3.75 & 2.97 & 0.447 \\
\hline NS3 & 0 & 0 & 1 & 0.03 & 0.05 & 0.92 & 5.77 & 4.11 & 0.492 \\
\hline NS4 & $1 / 2$ & $1 / 2$ & 0 & 0.12 & 0.14 & 0.75 & 7.97 & 3.33 & 2.202 \\
\hline NS5 & 0 & $1 / 2$ & $1 / 2$ & 0.03 & 0.14 & 0.84 & 4.39 & 3.43 & 1.108 \\
\hline NS6 & $1 / 2$ & 0 & $1 / 2$ & 0.12 & 0.05 & 0.84 & 8.87 & 3.81 & 0.971 \\
\hline NS7 & $2 / 3$ & $1 / 6$ & $1 / 6$ & 0.14 & 0.08 & 0.78 & 11.10 & 3.55 & 1.067 \\
\hline NS8 & $1 / 6$ & $2 / 3$ & $1 / 6$ & 0.06 & 0.16 & 0.78 & 6.81 & 3.58 & 1.178 \\
\hline NS9 & $1 / 6$ & $1 / 6$ & $2 / 3$ & 0.06 & 0.08 & 0.86 & 7.21 & 3.70 & 1.005 \\
\hline NS10 & $1 / 3$ & $1 / 3$ & $1 / 3$ & 0.09 & 0.11 & 0.81 & 6.91 & 3.70 & 0.734 \\
\hline
\end{tabular}

TABLE 7: Regression analysis of compressive strength of raw soil mixed with cement and gravel.

\begin{tabular}{lccccccc}
\hline Source parameter & $d_{f}$ & \multicolumn{2}{c}{$S S$} & & $M S$ & $F$ & $p>F$ \\
Regression & 3 & $S S_{R}$ & 54.31 & $M S_{R}$ & 18.104 & 28.73 & Remarkable \\
Deviation & 7 & $S S_{e}$ & 4.41 & $M S_{e}$ & 0.031 & & \\
Uncorrected summation & 10 & $S S_{T}$ & 58.72 & & & & \\
& $R^{2}$ & \multicolumn{2}{c}{0.9249} & & & & \\
\hline
\end{tabular}

TABLE 8: Estimation of the partial regression coefficient of $y_{1}$ regression equation for compressive strength of mixed cement and gravel modified with raw soil.

\begin{tabular}{lcclc}
\hline Regression term & Partial regression estimation & $t$-test & $p>\{t\}$ & Regression error of partial regression estimation \\
\hline$x_{1}$ & 12.23 & 21.34 & 0.0001 & 0.573 \\
$x_{2}$ & 4.13 & 7.22 & 0.0001 & 0.571 \\
$x_{3}$ & 5.92 & 10.32 & 0.0001 & 0.571 \\
\hline
\end{tabular}

Combining regression equation $y_{1}$, solving the equation $y_{\max }=11.51, y_{\min }=3.75$, range $\Delta=7.76, \overline{y_{1}}=7.43$, gradient $\nabla=1$, using Mathcad software, the results of equation $y_{1}$ are shown in Table 9 .

TABle 9: Compressive strength $y_{1}$ regression equation calculations.

\begin{tabular}{cccccccccccccccc}
\hline$y_{1}$ & \multicolumn{1}{c}{11} & \multicolumn{2}{c}{10} & \multicolumn{2}{c}{9} & \multicolumn{3}{c}{8} & \multicolumn{3}{c}{7} & \multicolumn{2}{c}{6} \\
\hline$x_{1}$ & 0.85 & 0.8 & 0.73 & 0.65 & 0.6 & 0.49 & 0.48 & 0.33 & 0.35 & 0.17 & 0.23 & 0.02 & 0.1 & 0 \\
$x_{2}$ & 0.15 & 0 & 0.27 & 0 & 0.4 & 0 & 0.52 & 0 & 0.65 & 0 & 0.77 & 0 & 0.9 & 0.51 \\
$x_{3}$ & 0 & 0.2 & 0 & 0.35 & 0 & 0.51 & 0 & 0.67 & 0 & 0.83 & 0 & 0.98 & 0 & 0.49 \\
\hline
\end{tabular}

The solution of the intersection point between the equation and the triangular coordinate axis is shown.

strength. The strength of gravel was higher than that of raw soil. Gravel particles here were mainly composed of quartz and the surfaces well encapsulated, adsorbed, and bonded with raw soil. However, when the gravel content increased, the gravel occupied a large amount of internal space, such that the soil particles did not bond well. With increased cement content, the hydration cementation of the cement was enhanced, which enhanced the cohesive force between soil particles and the material strength clearly increased. If only the compressive strength index was considered, the area of the enclosure area with $y_{1}=11$ and $x_{1}$ vertices was the optimal ratio area. From Figure 4, $0.8 \leq x_{1} \leq 1,0 \leq x_{2} \leq 0.15$, and $0 \leq x_{3} \leq 0.2$ were calculated from Section 3.1, with $0.17 \leq z_{1} \leq 0.2, \quad 0.05 \leq z_{2} \leq 0.08$, and $0.75 \leq z_{3} \leq 0.78$, and thus the optimal formula of cement, gravel, and raw soil was 0.18/0.06/0.76 (mass ratio, resp.).
(2) The regression analysis of response variable $y_{2}$ was carried out with reference to Table 6 . The calculation was simplified by examining the first-order polynomial for the regression model $\hat{y}=f(x)=a x_{1}+b x_{2}+c x_{3}$. The regression results showed the coefficient of determination at $R^{2}=0.9441$ by linear regression (Table 10). According to the $F$-test, the linear regression equation was significant and the primary regression model concluded to be scientific and reasonable. The polynomial coefficients calculated using MATLAB are shown in Table 11. The corresponding regression equation was $y_{2}=3.6 x_{1}+$ $3.08 x_{2}+4.04 x_{3}$.

According to the coordinates of the equation $y_{2}$ solution, a contour map corresponding to the equation was drawn in triangular coordinates using Origin 9.0 drawing software (Table 10, Figure 5). 


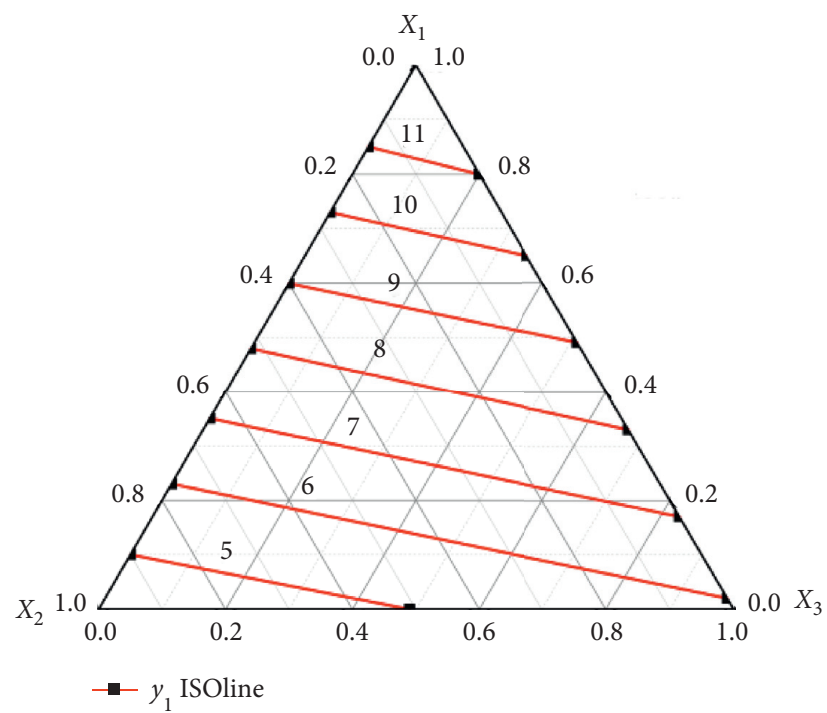

FIGURE 4: Isogram of compressive strength $y_{1}$ regression equation.

TABLE 10: Regression analysis of peak displacement of raw soil mixed with cement and gravel.

\begin{tabular}{lccccccc}
\hline Source parameter & $d_{f}$ & \multicolumn{2}{c}{$S S$} & \multicolumn{2}{c}{$M S$} & $F$ & $p>F$ \\
Regression & 3 & $S S_{R}$ & 0.94 & $M S_{R}$ & 0.3133 & 28.73 & Remarkable \\
Deviation & 7 & $S S_{e}$ & 0.12 & $M S_{e}$ & 0.0170 & & \\
Uncorrected summation & 10 & $S S_{T}$ & 1.06 & & & & \\
& $R^{2}$ & \multicolumn{2}{c}{0.9441} & & & & \\
\hline
\end{tabular}

TABLE 11: Estimation of the partial regression coefficient of $y_{2}$ regression equation for peak displacement of mixed cement and gravel modified with raw soil.

\begin{tabular}{lcccc}
\hline Regression term & Partial regression estimation & $t$-test & $p>\{t\}$ & Regression error of partial regression estimation \\
\hline$x_{1}$ & 3.6 & 36.85 & 0.0001 & 0.098 \\
$x_{2}$ & 3.08 & 31.57 & 0.0001 & 0.097 \\
$x_{3}$ & 4.04 & 41.38 & 0.0001 & 0.097 \\
\hline
\end{tabular}

Combining regression equation $y_{2}$, solving the equation $y_{\max }=4.11, y_{\min }=2.97$, range $\Delta=1.14, \overline{y_{2}}=3.57$, gradient $\nabla=0.1$, using Mathcad software, the results of equation $y_{2}$ are shown in Table 12 .

TABLE 12: Peak displacement $y_{2}$ regression equation calculations.

\begin{tabular}{|c|c|c|c|c|c|c|c|c|c|c|c|c|c|c|}
\hline$y_{2}$ & \multicolumn{2}{|c|}{4} & \multicolumn{2}{|c|}{3.9} & \multicolumn{2}{|c|}{3.8} & \multicolumn{2}{|c|}{3.7} & \multicolumn{2}{|c|}{3.6} & \multicolumn{2}{|c|}{3.5} & \multicolumn{2}{|c|}{3.4} \\
\hline$x_{1}$ & 0.1 & 0 & 0.32 & 0 & 0.55 & 0 & 0.77 & 0 & 1 & 0 & 0.8 & 0 & 0.62 & 0 \\
\hline$x_{2}$ & 0 & 0.05 & 0 & 0.15 & 0 & 0.25 & 0. & 0.35 & 0 & 0.45 & 0.2 & 0.56 & 0.38 & 0.67 \\
\hline$x_{3}$ & 0.9 & 0.95 & 0.68 & 0.85 & 0.45 & 0.75 & 0.23 & 0.65 & 0 & 0.55 & 0 & 0.44 & 0 & 0.33 \\
\hline$y_{2}$ & \multicolumn{2}{|c|}{3.3} & \multicolumn{2}{|c|}{3.2} & \multicolumn{2}{|c|}{3.1} & & & & & & & & \\
\hline$x_{1}$ & 0.42 & 0 & 0.23 & 0 & 0.04 & 0 & & & & & & & & \\
\hline$x_{2}$ & 0.58 & 0.77 & 0.77 & 0.87 & 0.96 & 0.97 & & & & & & & & \\
\hline$x_{3}$ & 0 & 0.23 & 0 & 0.14 & 0 & 0.03 & & & & & & & & \\
\hline
\end{tabular}

The solution of the intersection point between the equation and the triangular coordinate axis is shown.

Parameters $x_{1}, x_{2}$, and $x_{3}$ represented the admixtures of cement, gravel, and raw soil, respectively (Figure 5). The gradient of the isoline decreased from $x_{3}$ point to the $x_{1} x_{2}$ coordinate axis step by step. The average line of peak displacement was located on the middle line of the coordinate triangle, which showed that the raw soil content of these three admixtures played a major role in peak displacement.
With increased cement content, the hydration cementation of the cement was enhanced, which enhanced cohesive forces between soil particles and the peak displacement of the material decreased. The mean line was on the middle line of the coordinate triangle, which showed that the influences of gravel and cement on the peak displacement of specimens were basically the same. If only the peak displacement index 


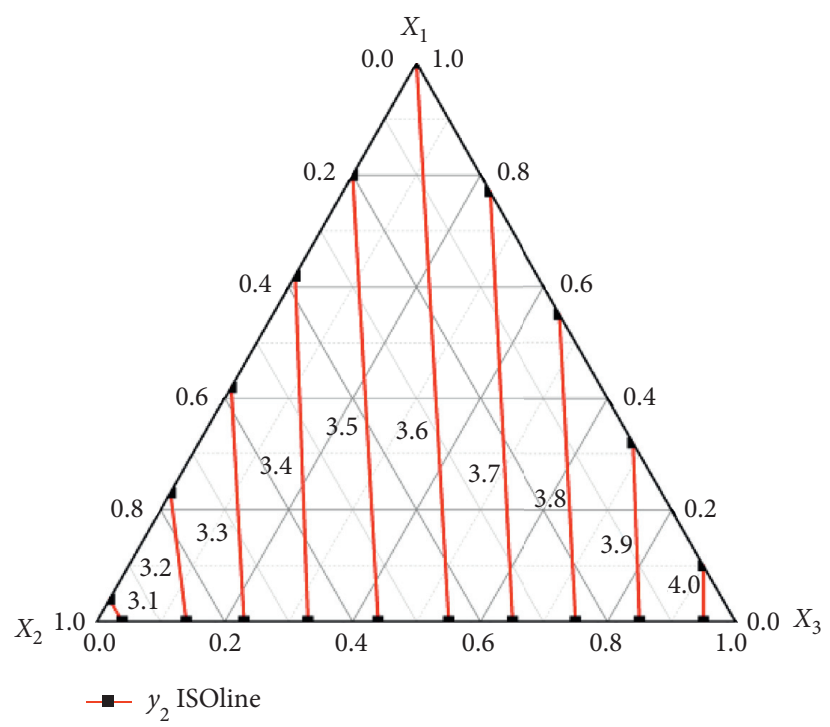

FIGURE 5: Isogram of peak displacement $y_{2}$ regression equation.

TABLE 13: Regression analysis of the standard deviation of raw soil mixed with cement and gravel.

\begin{tabular}{lccccccc}
\hline Source parameter & $d_{f}$ & & $S S$ & & $M S$ & $F$ & 12.14 \\
Regression & 3 & $S S_{R}$ & 3.28 & $M S_{R}$ & 1.093 & Remarkable \\
Deviation & 7 & $S S_{e}$ & 0.63 & $M S_{e}$ & 0.09 & \\
Uncorrected summation & 10 & $S S_{T}$ & 3.91 & & & & \\
& $R^{2}$ & \multicolumn{2}{c}{0.8387} & & & & \\
\hline
\end{tabular}

TABLE 14: Estimation of the partial regression coefficient of $y_{3}$ regression equation for the standard deviation of mixed cement and gravel modified with raw soil.

\begin{tabular}{lcccc}
\hline Regression term & Partial regression estimation & $t$-test & $p>\{t\}$ & Regression error of partial regression estimation \\
\hline$x_{1}$ & 1.51 & 4.36 & 0.0003 & 0.347 \\
$x_{2}$ & 1.04 & 2.98 & 0.002 & 0.346 \\
$x_{3}$ & 0.6 & 1.72 & 0.0129 & 0.346 \\
\hline
\end{tabular}

Combining regression equation $y_{3}$, solving the equation $y_{\max }=2.20, y_{\min }=0.447$, range $\Delta=1.755, \overline{y_{3}}=1.04$, gradient $\nabla=0.1$, using Mathcad software, the results of equation $y_{3}$ are shown in Table 15 .

TABLE 15: Standard deviation $y_{3}$ regression equation calculations.

\begin{tabular}{lccccccccccc}
\hline$y_{2}$ & & 1.5 & \multicolumn{2}{c}{1.3} & & 1.1 & & 0.9 & 0.7 \\
\hline$x_{1}$ & 0.98 & 0.97 & 0.77 & 0.55 & 0.55 & 0.98 & 0.97 & 0.77 & 0.55 \\
$x_{2}$ & 0 & 0.03 & 0 & 0.45 & 0 & 0 & 0.03 & 0 & 0.45 \\
$x_{3}$ & 0.02 & 0 & 0.23 & 0 & 0.45 & 0.02 & 0 & 0.23 & 0 \\
\hline
\end{tabular}

The solution of the intersection point between the equation and the triangular coordinate axis is shown.

was considered, the area of the siege with $y_{2}=4$ and $x_{3}$ vertices was the optimal ratio area. From Figure 5, $0 \leq x_{1} \leq 0.1,0 \leq x_{2} \leq 0.05$, and $0.9 \leq x_{3} \leq 1$ were calculated from Section 3.1, with $0.03 \leq z_{1} \leq 0.05,0.05 \leq z_{2} \leq 0.06$, and $0.9 \leq z_{3} \leq 0.92$, and thus the optimal formula for cement, gravel, and raw soil was 0.04/0.06/0.9 (mass ratio, resp.).

(3) The regression analysis of response variable $y_{3}$ was carried out with reference to Table 6 . The calculation was simplified by examining the first-order polynomial for the regression model $\hat{y}=f(x)=a x_{1}+b x_{2}+c x_{3}$. The regression results showed the coefficient of determination $R^{2}=0.8387$ by linear regression (Table 13 ). According to the $F$-test, the linear regression equation was significant and the primary regression model concluded to be scientific and reasonable. The polynomial coefficients calculated using MATLAB are shown in Table 14. The corresponding regression equation was $y_{3}=1.51 x_{1}+$ $1.04 x_{2}+0.6 x_{3}$. 


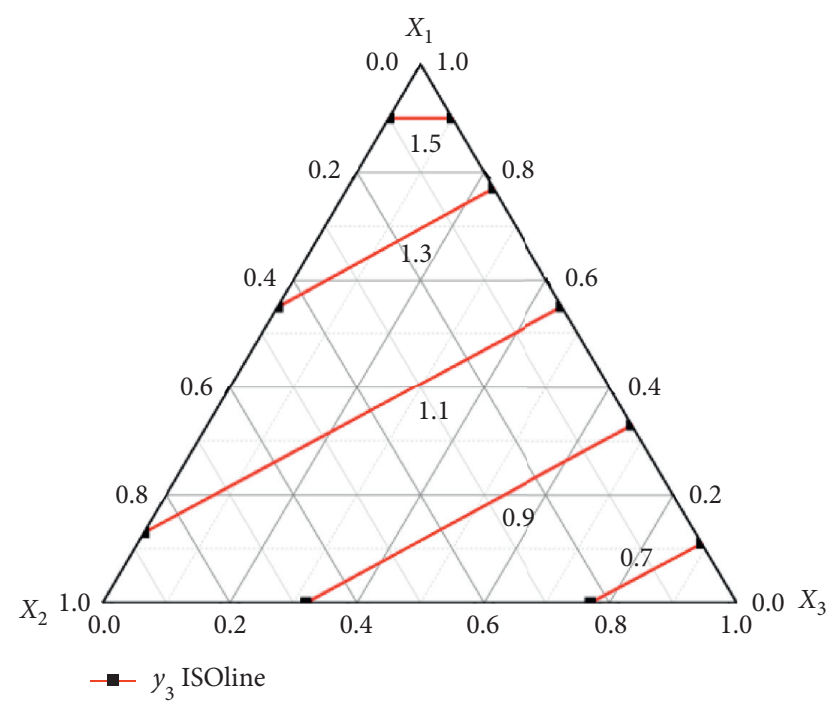

Figure 6: Isogram of standard deviation $y_{3}$ regression equation.

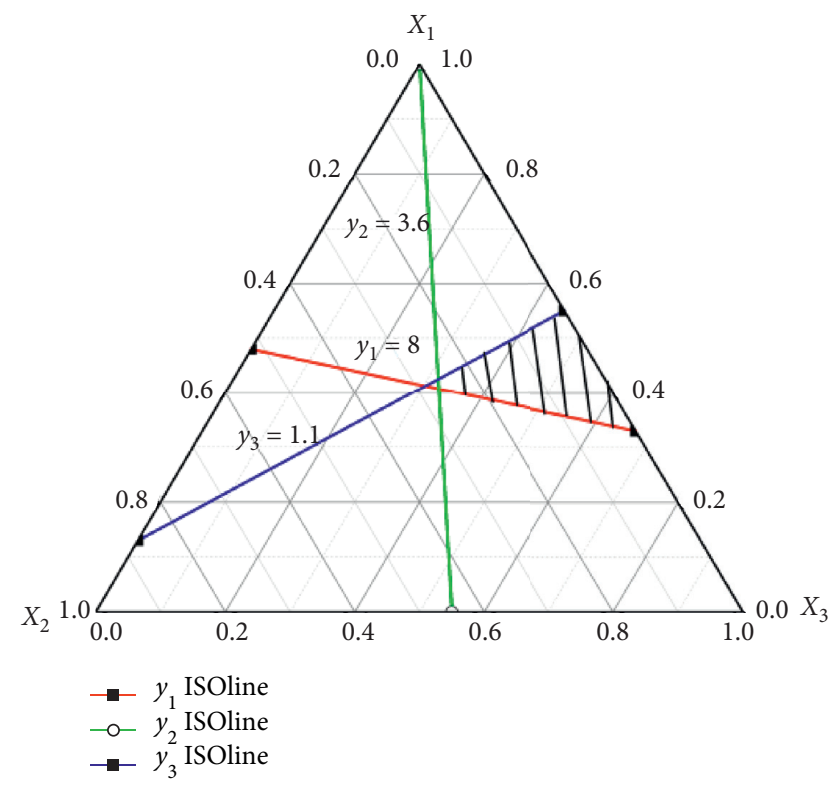

FIGURE 7: Optimal formulation region for synthesizing the three reaction variables $y_{1}, y_{2}$, and $y_{3}$.

According to the coordinates of the equation solution in Table 15, a contour map corresponding to the equation was drawn in triangular coordinates using Origin 9.0 drawing software (Figure 6).

Parameters $x_{1}, x_{2}$, and $x_{3}$ represented the admixtures of cement, gravel, and raw soil, respectively (Figure 6). The gradient of the isoline decreased from $x_{1}$ point to the $x_{2} x_{3}$ coordinate axis step by step, which showed that the cement content of these three admixtures played a major role in the standard deviation. If only the standard deviation index was considered, the area of the siege with $y_{3}=7$ and $x_{3}$ vertices was the optimal ratio area. From Figure 6, $0 \leq x_{1} \leq 0.11,0 \leq x_{2} \leq 0.23$, and $0.77 \leq x_{3} \leq 1$ were calculated from Section 3.1, with $0.03 \leq z_{1} \leq 0.05,0.05 \leq z_{2} \leq 0.09$, and $0.88 \leq z_{3} \leq 0.92$, and thus the optimal formula of cement, gravel, and raw soil was 0.04/0.07/0.89 (mass ratio, resp.).

(4) The optimal formulation should satisfy the three reaction variables at the same time. The strength of specimens also showed the material load resistance. The peak displacement of the specimen reflected the material deformation performance. The standard deviation of a test reflected the stability and discreteness of the material internal structure. Thus, a superposition of Figures 4, 5, and 6 was studied. The optimal formulation area is shown in Figure 7. Here, $y_{3}=1.1, y_{2}=3.6$, and $y_{1}=8$ in the shadow of the siege; solution of the equations $0.33 \leq x_{1} \leq 0.55,0 \leq x_{2} \leq 0.28$, and $0.3 \leq x_{3} \leq 0.67$ were calculated from Section 3.1, with $0.08 \leq z_{1} \leq 0.12$ and $0.8 \leq z_{3} \leq 0.86$. Thus, the optimal formula for the cement, gravel, and raw soil was $0.1 / 0.08 / 0.82$ (mass ratio, resp.).

\section{Conclusion}

The compressive strength of raw soil modified by cement and gravel is significantly higher than that of plain soil. The compressive strength is $1.16-3.55$ times that of raw soil. If the cement content is fixed, the compressive strength of the specimen decreases with the increase of the stone content. If the stone content is fixed, the compressive strength increases with the increase of cement content.

In this study, the single lattice model formulation design method was introduced to effectively improve and control raw soil modification formulation tests affected by many factors. Through regression analysis, the isoline equation image solution was best for verifying this method, which showed that this method was feasible for the test study of raw soil modification. Using the combination of MATLAB modeling software, Mathcad calculation software, and Origin drawing software, programming calculations were performed to improve the efficiency of mathematical calculation.

According to the equation solutions, a contour map of the triangular coordinate system was drawn, which effectively reflected the influence of the admixture on the results. The content of cement and gravel had a significant influence on the compressive strength and standard deviation of specimens. The raw soil content only affected peak displacement.

Considering the compressive strength, peak displacement, and standard deviation, the optimal mass ratio of gravel, cement, and raw soil was 0.1/0.08/0.82 (mass ratio, resp.).

The formulation model provided the method and basis for the standard method of raw soil mixed modification testing.

\section{Data Availability}

All data generated or analyzed during this study are included in this article.

\section{Conflicts of Interest}

The authors declare that they have no conflicts of interest. 


\section{Acknowledgments}

The research for this project was supported by the National Natural Science Foundation of China, for the "Study on the Standard Test Method of Materials and Masonry Based on Raw-Soil" (51478043), the Shaanxi Natural Science Basic Research Program (2019JQ-554), and Natural Fund of Shaanxi Provincial Department of Education (20JK0816). Their financial support is highly appreciated.

\section{References}

[1] M. Hall, R. Lindsay, and Krayenhoff, Modern Earth Buildings, Woodhead Publishing, Cambridge, UK, 2012.

[2] L. Keefe, M. Earth Building: Methods and Materials, Repair and Conservation, Taylor \& Francis, Oxfordshire, England, 2005.

[3] H. V. Damme and H. Houben, "Earth concrete. Stabilization revisited," Journal of Cement and Concrete Research, vol. 24, no. 6, pp. 74-80, 2017.

[4] A. P. Da Silva Milani and L. C. Labaki, "Physical, mechanical, and thermal performance of cement-stabilized rammed earthrice husk ash walls," Journal of Materials in Civil Engineering, vol. 24, no. 6, pp. 775-782, 2012.

[5] Y. Wang, J. Zhong, Y. Shi, D. Quan, and X. Yue, "Review of overseas research on raw-soil structure," China Civil Engineering Journal, vol. 48, no. 6, pp. 81-87, 2015.

[6] K. Zhang, Y. Wang, J. Liang, Y. Zhang, and J. Zhong, "Experimental study on seismic performance of rammed earth wall reinforced with brick columns and reinforcement mortar belt," Journal of Xi'an University of Architecture \& Technology, vol. 47, pp. 382-385, 2015.

[7] S. Burroughs, "Recommendations for the selection, stabilization, and compaction of soil for rammed earth wall construction," Journal of Green Building, vol. 5, no. 1, pp. 101-114, 2010.

[8] R. Bahar, M. Benazzoug, and S. Kenai, "Performance of compacted cement-stabilised soil," Cement and Concrete Composites, vol. 26, no. 7, pp. 811-820, 2004.

[9] M. R. Hall, K. B. Najim, and P. Keikhaei Dehdezi, "Soil stabilisation and earth construction: materials, properties and techniques," Modern Earth Buildings, vol. 25, no. 25, pp. 222-255, 2012.

[10] D. Ciancio, P. Jaquin, and P. Walker, "Advances on the assessment of soil suitability for rammed earth," Construction and Building Materials, vol. 42, no. 5, pp. 40-47, 2013.

[11] V. Maniatidis and P. Walker, "A review of rammed earth construction," in Proceedings of the DTI Projet Report, Bath, England, May 2003.

[12] C. Jayasinghe and N. Kamaladasa, "Compressive strength characteristics of cement stabilized rammed earth walls," Construction and Building Materials, vol. 21, no. 11, pp. 1971-1976, 2007.

[13] J. K. Mitcheli and R. K. Katti, "Soil improvement-general report," in Proceedings of the Tenth ICSMFE, vol. 4, pp. 567-575, Stockholm, Sweden, 1981.

[14] A. B. Ngowi, "Improving the traditional earth construction: a case study of Botswana," Journal of Construction and Building Materials, vol. 11, no. 1, pp. 1-7, 1997.

[15] Q.-B. Bui, J.-C. Morel, S. Hans, and N. Meunier, "Compression behaviour of non-industrial materials in civil engineering by three scale experiments: the case of rammed earth," Materials and Structures, vol. 42, no. 8, pp. 1101-1116, 2009.
[16] S. Ziegler, D. Leshchinsky, H. I. Ling, and E. B. Perry, "Effect of short polymeric fibers on crack development in clays," Soils and Foundations, vol. 38, no. 1, pp. 247-253, 1998.

[17] Y. Wang, Q. Wu, T. Wang et al., "Analysis for effects of gravel contents on compression behavior of raw-soil specimens," Journal of Building Structure, vol. 47, no. 15, pp. 76-79, 2017.

[18] Y.-X. Zhao, Q. Gao, and J.-N. Wang, "An approach for determining an appropriate assumed distribution of fatigue life under limited data," Reliability Engineering and System Safety, vol. 67 , no. 2, pp. 1-7, 2000.

[19] H. P. Kirchner, R. M. Gruver, and W. A. Sotter, "Fracture stress-mirror size relations for polycrystalline ceramics," Philosophical Magazine, vol. 33, no. 5, pp. 775-780, 1976.

[20] L. Sotter, M. Shi-Tao, and T. U. Jian-Wei, "Determination method on tensile strength of GERP bar based on three parameter weibull distribution," Journal of Wuhan University of Technology, vol. 37, no. 9, pp. 72-77, 2015.

[21] China Planning Publishing House, GBT50123-1999, Geotechnical Test Method Standard, China Planning Publishing House, Beijing, China, 1999.

[22] Y.-H. Wang, M. A. Peng-bo, K. Zhang et al., "Test measurement of optimum moisture content of modified raw-soil material," Journal of Xi'an University of Science and Technology, vol. 35, no. 6, pp. 768-773, 2015.

[23] K. Zhang, B. Lu, Y. Wang, Z. Lei, and Z. Yang, "Experimental strength of earth-based construction materials in different regions of China," Advances in Materials Science and Engineering, vol. 2019, no. 5, Article ID 8130743, 9 pages, 2019. 